\title{
Effects of Age, Sex, Disease, and Exercise Training on Lip Muscle Strength
}

\author{
Vickie Wong, Takashi Abe *(D), Robert W. Spitz, Zachary W. Bell, Yujiro Yamada, \\ Raksha N. Chatakondi and Jeremy P. Loenneke \\ Department of Health, Exercise Science, \& Recreation Management, Kevser Ermin Applied Physiology \\ Laboratory, The University of Mississippi, University, MS 38677, USA; vwong@go.olemiss.edu (V.W.); \\ rwspitz@go.olemiss.edu (R.W.S.); zwbell@go.olemiss.edu (Z.W.B.); yyamada1@go.olemiss.edu (Y.Y.); \\ rnchatak@go.olemiss.edu (B.N.C.); jploenne@olemiss.edu (J.P.L.) \\ * Correspondence: t12abe@gmail.com; Tel.: +1 (662) 915-5521; Fax: +1 (662) 915-5525
}

\begin{abstract}
Lip muscle strength has been shown to influence daily functional activities such as facial expression, speech production, and eating. In this review, recent literature regarding lip strength and exercise training responses are summarized, highlighting the influence of sex, age, and disease (e.g., stroke). A search using five electronic databases was conducted. Twelve studies were identified from the search, which included five studies using healthy adults and seven studies using patients with diseases or chronic ailments. Regardless of the population, lip strength training multiple times a day for a relatively short term ( $<24$ weeks) has resulted in improvements of lip muscle strength. This change in lip strength has been observed in both young and old participants. Although changes in strength have been observed in both men and women, we are unaware of any studies that have tested whether there are sex differences in this response. The same directional change can be expected for patients with stroke and patients with lip incompetence, but the magnitude of the training effect seems to be higher in healthy people.
\end{abstract}

Keywords: lip strengthening exercise; lip-closing strength; orbicularis oris

\section{Introduction}

Lip strength and function is important to consider because it can influence daily activities. This includes facial expression, speech production, eating behaviors and even indirectly influences swallowing capacity. Swallowing disorders (dysphagia) are a common condition in older adults, especially those who have had a stroke and those with neurological disease (e.g., Parkinson's disease and Alzheimer's disease). It is estimated that swallowing disorders occur in up to $40 \%$ of adults over the age of 60 [1]. Further, the prevalence of swallowing disorders was reported to range between $8.1 \%$ and $80 \%$ in stroke survivors and between $11 \%$ and $81 \%$ in those with Parkinson's disease [2]. Dysphagia can also unfavorably impact the quality of life. Patients with swallowing dysfunction may experience uneasiness and panic during mealtimes, which may lead to malnutrition since eating becomes less enjoyable [3].

The normal mechanism of swallowing begins with the closure of the mouth/lips. In the first phase of preparing to swallow, the oral phase, a majority of abnormalities are caused by a reduction of lip closure force that proceeds with muscular dysfunction of the orofacial complex lip muscles [4]. The oral phase involves a chewing process in which food is crushed and ground using the teeth. The secretion of saliva containing enzymes from the salivary glands assists with the formation of a sufficient bolus to aid in swallowing. The oral vestibule pressure generated by the lips and cheeks during chewing is thought to help push food towards the back of the mouth [5]. The abnormalities in the second phase of 
swallowing, the pharyngeal phase, are mainly due to a combination of movements from the tongue and palatal defects. Thus, prior to swallowing, lip function during the initial oral phase is of great importance and can be influenced by a variety of factors.

The muscle involved in lip closure is mainly the orbicularis oris muscle, which is a complex striated muscle that surrounds the oral cleft [6]. The loss of function in the orbicularis oris muscle may result in a detrimental decline to daily functional activities that can originate with a decrease of complete lip closure and function $[7,8]$. The decline of lip closure can negatively influence various behaviors, not only during the oral phase of swallowing but also when forming facial expression, during speech, while sleeping [9], and in the presence of halitosis [10]. However, lip muscle strength can be improved by lip exercise training [11]. Previous studies have recruited from a variety of populations including healthy adults and diseased patients $[7,9,11-13]$. It may be necessary to consider participant characteristics in order to better understand the long-term effects of lip exercise. In addition, the equipment used for training protocols is not consistent across studies. Thus, the purpose of this review is to: 1) introduce the characteristics of training devices used in previous studies; 2 ) provide information about the effects of lip exercise training focused on adult individuals with and without stroke or lip incompetence; 3) discuss possible sex differences; and 4) discuss the effect of aging on these training responses. In addition, the baseline characteristics of lip muscle strength from cross-sectional studies have been added to the sections discussing sex differences, the effects of age, and disease.

\section{Study Selection}

Studies of lip strength training in healthy adults and patients with diseases or chronic ailments affecting the facial muscles were included. In order to be included, the study had to: (1) have an exercise program for the facial muscles (including studies using electrical stimulation); (2) include individuals 18 years old and older; and (3) be written in English.

The initial search identified 397 articles from Embase, Google Scholar, Pub Med, Scopus, and Cochrane Central using the following phrases: "lip strength training", "lip closure training", and "orbicularis oris and training". An additional two articles were retrieved through manual searches through the reference lists. A total of 384 articles were excluded based on duplication and screening the titles and abstracts. After full-text articles were reviewed for eligibility, 12 were included in the final review (Table 1; Table 2). 
Table 1. Lip strength training in healthy adults.

\begin{tabular}{|c|c|c|c|c|c|c|c|}
\hline Reference & Participants & Duration & $\begin{array}{c}\text { Frequency } \\
\text { (days/week) }\end{array}$ & Control & $\begin{array}{l}\text { Measurement } \\
\text { Time Points }\end{array}$ & Results & Notes \\
\hline Ibrahim et al. (12) & $\begin{array}{c}13 \text { women } \\
\text { (40 years and up) }\end{array}$ & 14 or 24 weeks & 4/week & No & $\begin{array}{l}\text { Baseline and } \\
\text { 14/24 weeks }\end{array}$ & $\begin{array}{l}\text { Labial closure strength increased } \\
\text { week } 1 \text { to } 14 \text { and there was also an } \\
\text { increase from week } 1 \text { to } 24(\mathrm{n}=11)\end{array}$ & $\begin{array}{c}11 / 17 \text { women continued } \\
\text { exercise for additional } \\
10 \text { weeks }\end{array}$ \\
\hline Arakawa et al. (22) & $\begin{array}{l}12 \text { men and } 12 \text { women } \\
(25.1 \pm 3.0 \text { years })\end{array}$ & 2 months & 7/week & Yes & $\begin{array}{l}\text { Baseline, } 1 \text {, and } 2 \\
\text { months }\end{array}$ & $\begin{array}{l}\text { Labial closure strength increased at } \\
\text { month } 1 \text { and continued to increase } \\
\text { in month } 2\end{array}$ & $\begin{array}{l}\text { A control group was } \\
\text { included }\end{array}$ \\
\hline Kaede et al. (7) & $\begin{array}{c}10 \text { men and } \\
10 \text { women } \\
(26.7 \pm 1.8 \text { to } \\
28.5 \pm 1.5 \text { years })\end{array}$ & 4 weeks & 7/week & Yes & $\begin{array}{l}\text { Baseline, during, } \\
\text { and after every } \\
\text { training week }\end{array}$ & $\begin{array}{c}\text { Total lip-closing force increased at } \\
3 \text { and } 4 \text { weeks in training } \\
\text { group vs. control }\end{array}$ & $\begin{array}{l}\text { The training group } \\
\text { decreased in force after } \\
\text { a week of no training }\end{array}$ \\
\hline Fujiwara et al. (23) & $\begin{array}{l}66 \text { Japanese women } \\
\text { (29.6 years) }\end{array}$ & 7 days & 7/week & Yes & Baseline, 6,8 days & $\begin{array}{l}\text { No difference between groups but } \\
\text { there was an increase with time }\end{array}$ & \\
\hline Takamoto et al. (9) & $\begin{array}{l}18 \text { men and } 2 \text { women } \\
(86.3 \pm 1 \text { years })\end{array}$ & 4 weeks & 7/week & Yes & $\begin{array}{l}\text { Baseline and } 4 \\
\text { weeks }\end{array}$ & $\begin{array}{l}\text { Lip-closure force increased, less } \\
\text { time to eat, food spilling decreased, } \\
\text { sleep duration decreased, and } \\
\text { cerebral hemodynamics increased }\end{array}$ & $\begin{array}{l}\text { A control group } \\
\text { was included }\end{array}$ \\
\hline
\end{tabular}


Table 2. Lip strength training in adults with health complications.

\begin{tabular}{|c|c|c|c|c|c|c|c|}
\hline Reference & Participants & Duration & $\begin{array}{c}\text { Frequency } \\
\text { (days/week) }\end{array}$ & Control & $\begin{array}{c}\text { Measurement Time } \\
\text { Points }\end{array}$ & Results & Notes \\
\hline $\begin{array}{l}\text { Hagg and Anniko } \\
\text { (11) }\end{array}$ & 30 stroke patients ( $49-88$ years) & 5-8 weeks & Unknown & No & Baseline and $>5$ weeks & Increase in lip force and increase in swallowing capacity & \\
\hline Ohtsuka et al. (29) & $\begin{array}{l}12 \text { men and } 6 \text { women } \\
(25 \pm 2.5 \text { years) with lip } \\
\text { incompetence }\end{array}$ & 4 weeks & 7/week & No & $\begin{array}{c}\text { Baseline, } 2 \text {, and } \\
4 \text { weeks of training, } \\
\text { and } 4 \text { and } 8 \text { weeks } \\
\text { from termination of } \\
\text { training }\end{array}$ & $\begin{array}{l}\text { Sealed lip ratio increased at } 2 \text { and } 4 \text { weeks of training } \\
\text { and was not different from the end of training to } 4 \text { or } \\
8 \text { weeks from the termination of training }\end{array}$ & \\
\hline $\begin{array}{c}\text { Yoshizawa et al. } \\
\text { (30) }\end{array}$ & $\begin{array}{l}10 \text { men and } 10 \text { women } \\
(23.6 \pm 2.3 \text { years }) \text { with lip } \\
\text { incompetence }\end{array}$ & 4 weeks & 7/week & No & $\begin{array}{l}\text { Baseline, } 2 \text {, and } \\
4 \text { weeks }\end{array}$ & $\begin{array}{l}\text { Strength and endurance of orbicularis oris increased } \\
\text { gradually during the training period and decreased } \\
\text { slightly during the post-trainingperiod }\end{array}$ & \\
\hline Byeon (16) & $\begin{array}{l}34 \text { women and } 14 \text { men with } \\
\text { dysphagia in an experimental } \\
\text { and control group } \\
(62.5 \pm 6.5 \text { and } 64.1 \pm 7.1)\end{array}$ & 3 weeks & 5/week & Yes & Baseline and 3 weeks & $\begin{array}{l}\text { Lip compression increased in the } \\
\text { experimental group vs. control }\end{array}$ & \\
\hline Oh et al. (27) & 8 patients & 4 weeks & 5/week & No & Baseline and 4 weeks & Lip strength increased & $\begin{array}{c}\text { Gender and age were } \\
\text { not reported }\end{array}$ \\
\hline $\begin{array}{c}\text { Yoshizawa et al. } \\
\text { (31) }\end{array}$ & $\begin{array}{c}14 \text { men and } 11 \text { women } \\
\text { (24.5 } \pm 2.6 \text { years) separated into } \\
\text { groups of lip incompetence and } \\
\text { competence }\end{array}$ & 4 weeks & 7/week & No & $\begin{array}{l}\text { Baseline, } 2,4,8 \text {, and } \\
12 \text { weeks }\end{array}$ & $\begin{array}{l}\text { Lip incompetence could be improved by hypoxic } \\
\text { liptraining only }\end{array}$ & $\begin{array}{l}\text { Individuals with lip } \\
\text { incompetence need } \\
\text { greater orbicularis oris } \\
\text { muscle activity to keep } \\
\text { their lips closed }\end{array}$ \\
\hline Park et al. (13) & $\begin{array}{l}10 \text { patients with swallowing } \\
\text { disorder and facial palsy after } \\
\text { stroke }\end{array}$ & 4 weeks & 5/week & No & Baseline and 4 weeks & Lip-closure force increased & \\
\hline Saleem et al. (32) & $\begin{array}{l}9 \text { women and } 4 \text { men } \\
(69.8 \pm 6.1 \text { year) with } \\
\text { periodontaldisease }\end{array}$ & 6 weeks & 7/week & No & $\begin{array}{l}\text { Baseline, } 1 \text {, and } \\
6 \text { months }\end{array}$ & Lip force increased 1 and 6 months after training & \\
\hline
\end{tabular}




\section{Devices Used in Lip Exercise Intervention}

Various tools have been used in lip closure training. Devices used in previous studies include (1) Lip trainers, (2) oral screens, (3) the Iowa Oral Performance Instrument (IOPI) and, (4) the JMS device, which is similar to the IOPI. All the devices reported in the previous studies have resulted in an increase in lip-closing force in young and older adults, suggesting that lip function can be improved by these various training methods. Although there does not seem to be any past literature comparing the devices pertaining to the lip muscles, there are suggestions that the size of the oral screens influences the lip force produced [14].

Lip trainers are commercially available and are marketed towards the improvement and maintenance of health and beauty. When used for lip muscle strength training [7,12], the device is set in front of closed teeth behind the upper and lower lips (see the pictures in ref. 6). An attachment handle is connected to the top and bottom of the device to allow users to gently pull the device, generating a force against the lip muscles. The original instructions for the usage of the device are to maintain a clenched lip position on the lip training device for three minutes, 3-4 times a day [7,12]. The exercise intensity is not specified and, due to the device's structure, it is not adjustable (Table 3).

Table 3. Training program including exercise intensity, volume, and rest interval between sets of lip strength training.

\begin{tabular}{|c|c|c|c|c|}
\hline Reference & Device & Intensity & Volume & Rest Interval \\
\hline \multicolumn{5}{|l|}{ Healthy adults } \\
\hline Ibrahim et al. (12) & Lip trainer & Unknown & $3 \min \times 4$ sets & Unknown \\
\hline Kaede et al. (7) & Lip trainer & Unknown & $3 \mathrm{~min} \times 3$ sets & Unknown \\
\hline Takamoto et al. (9) & Lip trainer & Unknown (load reported as $4 \mathrm{~N}$ ) & $3 \mathrm{~min} \times 3$ times & Unknown \\
\hline \multicolumn{5}{|l|}{ Patients with disease } \\
\hline $\begin{array}{l}\text { Hagg \& Anniko } \\
\text { (11) }\end{array}$ & Oral screen & Unknown & $5-10 \mathrm{~s} \times 3$ reps, 3 times daily & Unknown \\
\hline Ohtsuka et al. (29) & Oral screen & $50 \%$ or $80 \%$ MTS & $\begin{array}{c}5 \mathrm{~s} \times 20 \text { reps }(50 \%) \text { or } \\
5 \mathrm{~s} \times 5 \text { reps }(80 \%) \text { or } \\
5 \mathrm{~s} \times 5 \text { reps }(50 \%)\end{array}$ & $5 \mathrm{~s}$ \\
\hline Byeon (16) & IOPI & Unknown & $\begin{array}{c}30 \text { min sessions of } 9 \\
\text { exercises with } 2 \text { specifically } \\
\text { targeting the lips (lip closing, } \\
\text { lip protrusion) }\end{array}$ & Unknown \\
\hline Park et al. (13) & IOPI & $70 \% \mathrm{MVC}$ & 30 reps & Unknown \\
\hline Saleem et al. (32) & Lip trainer & Unknown & $3 \mathrm{~min}, 3$ times daily & Unknown \\
\hline
\end{tabular}

The Oral Screen is a custom-made acrylic screen that extends backward to the front of the user's teeth and behind the user's upper and lower lips (see the figures in ref. 14). This lip training device has an attached metal loop which encourages the user to manually pull the device against the lips. It has also been used to rehabilitate patients with oral motor dysfunction [11]. Different-sized oral screens have been implemented for research and clinical use; however, the majority of studies have not determined exercise intensity (Table 3).

The IOPI, developed in 2001, is a tongue and cheek strength measurement device that has been modified to also measure the strength of the lip muscles. Thus, it can be used to strengthen the lip muscles with its biofeedback feature for oral motor exercise [15]. This device, unlike the previous devices mentioned, provides biofeedback digitally in kilopascal units. Thus, unlike the Lip trainers, this device can prescribe a set intensity for lip strength training. This instrument has been used 
in research for lip strengthening protocols and evaluations [13,16]. The IOPI measures force using a tongue bulb. A method that has been implemented for the assessment in lip muscle strength requires placing the bulb between two wooden blades $[17,18]$. This configuration would allow the distribution of the pressure, exerted by the lips, to be even across the entire surface of the bulb.

\section{The Influence of Sex on Baseline Lip Strength and in Response to Training}

\subsection{Sex Differences in Baseline Lip Strength in Healthy Adults}

Lip strength measurements, using the IOPI bulb placed between two wooden blades, have been found to be greater for men than for women [18-20]. For example, a study measured 171 participants (men and women) and reported that maximal lip compression, measured via IOPI, was higher in men $(33.8 \mathrm{kPa})$ than in women $(22.4 \mathrm{kPa})$ [18]. However, one study with 120 participants separated into three age groups and by sex did not observe a lip strength difference between men and women [21].

\subsection{Influence of Sex on Lip Training Responses in Healthy Adults}

Of the previous studies included, three studies included both men and women pooled together [7,9,22], and two studies [12,23] included only women (Table 1). Four of the five studies included control groups to better indicate if there was a difference in lip strength with training $[7,9,22,23]$, while the other defined a change as anything that exceeded the baseline value. A Lip trainer was used for training in three studies (Table 3). For example, lip-closure strength increased about $4 \mathrm{~N}$ (relative change of $68 \%$ ) following 14 weeks of lip training and continued to increase about $3 \mathrm{~N}$ for those participants in the women group that continued lip training for another 10 weeks [12]. Healthy men and women using the Lip trainer also observed increases in lip-closing force after four weeks when compared to a control group at the same time point [7]. One study reported the effect of tongue rotation exercise training on lip-closure strength in men and women [22]. The authors found that lip strength was increased by about $4.2 \mathrm{kPa}$ (relative change of $29.7 \%$ ) in men and about $3.5 \mathrm{kPa}$ (relative change of $34.3 \%$ ) in women after 3 months of training. To our knowledge, there has been no direct study to discuss the possible sex differences in training adaptations.

\section{Differences in Baseline Lip Strength and in Response to Training between Young and Older Adults}

\subsection{Age-Related Differences in Baseline Lip Strength in Healthy Adults}

Lip force measured through different methods does not appear to differ with age in a healthy population. For example, a study by Clark and Solomon [18] compared lip compression strength using the IOPI in three age groups, i.e., young (18-29 years), middle-aged (30-59 years), and old (60-89 years) adults. The authors reported that there was no difference in lip strength among the three groups (young $=27.5 \mathrm{kPa}$, middle-aged $=27.0 \mathrm{kPa}$, and old $=31.9 \mathrm{kPa}$ ). The maintenance of lip strength until older age may be due to the activity of the lip muscles during daily chewing and swallowing. For example, an electromyographic (EMG) study showed that during swallowing of saliva, an action that is repeated about 600-3000 times each day, EMG activity of the orbicularis oris superior muscle was $50-60 \%$ of maximal contraction [24]. However, it is unclear whether these activities of the lips persist in very old people. Thus, it may be possible that how the age is divided may affect the interpretation. Another study compared differences in lip strength (measured via IOPI) in four age groups [25]. In both men and women, the lip strength values of the young (20-39 years), middle-age (40-59 years), and old (60-79 years) individuals were not different from one another but were different from that of the very old group ( $\geq 80$ years) [25]. Longitudinal studies are needed to confirm the results of the cross-sectional studies described above. Future research is desired. 


\subsection{Influence of Age on Lip Training Responses in Healthy Adults}

Five studies included interventions in lip strength training in healthy adults (Table 1). Three of the studies used young adults [7,22,23], and the other two included middle-aged and older adults [9,12]. Training from as short as seven days to as long as two months resulted in an increase in lip strength in healthy participants. A variety of methods have been implemented for lip strength training, such as: (1) lip trainers [7,9,12], (2) oral screens [23], and even (3) one's own tongue [22].

Multidirectional lip-closing force in young women has been shown to increase after short-term lip training. The effects of the application of low (200 grams) and high loads (400 grams) using bottled water attached by a string to an intra-oral plate in the oral vestibule were compared. Both training groups showed an increase in lip-closing force when compared to the control group, and the change did not differ between the two training groups [23]. These results would suggest that a very short-term program (two times a day for approximately one week) may increase the lip-closing force. Kaede et al. [7] also used the multidirectional lip-closing force measurement device to measure lip strength. After four weeks of training using a Lip trainer, changes in total lip-closing force were increased at week 3 and 4 when compared to a control group. A marked increase of about $40 \%$ was noted at the completion of the four-week training period. Further, they reported that the time course of training adaptations may not be the same for the upper lip and the lower lip.

Similar to young healthy adults, when very old residents (mean age 86 years) from an elder care facility completed lip strength training using the lip trainer, maximal lip-closure force increased (4.66 to $6.77 \mathrm{~N}$, relative change of $45 \%$ ) following 4 weeks of training [9]. In addition, those authors observed improvements in the time of eating (14.9 to 12.6 seconds) and food spilling ( 3.47 to 1.44 times/mouthful) compared to a control group. Ibrahim and colleagues [12] found that lip-closure strength increased in healthy women ( $\geq 40$ years) from the first week to 14 weeks (5.7 to $9.6 \mathrm{~N}$, relative change of $68 \%$ ) of training and from the first week to 24 weeks ( 4.9 to $12.9 \mathrm{~N}$, relative change of $163 \%$ ) of training for those that continued the training intervention also using the lip trainer as a training device for improving lip strength. The pre-values are different because those who did not continue the training after 14 weeks were not included in the comparison from week one to 24 . These results indicate that lip strength values may see a consistent and progressive increase with the continuation of the exercise regime. However, whether there is a difference in the training response between healthy young and older adults has yet to be determined. A cross-sectional study [18] shows the wide range of variation in lip strength in each age group (range between 12 and $73 \mathrm{kPa}$ in young adults, between 13 and $74 \mathrm{kPa}$ in middle-aged adults, and between 15 and $62 \mathrm{kPa}$ in older adults). In contrast, a short-term intervention improves lip muscle strength, but the magnitude of improvement reported in the previous studies does not seem to be as high when compared to the range of the variation in lip strength. Therefore, it would seem that if a healthy individual has lower lip compression values, training would increase that strength but may not increase it enough to make it comparable to that of someone who already has a high lip compression strength.

\section{Lip Training Response in Patients with Disease}

\subsection{Differences in Lip Muscle Function in Patients with Disease}

It is well known that an inability to close the lip muscles results in food being expelled from the corners of the mouth, which impairs swallowing [4,11]. Both impaired lip strength and dysphagia have been observed even when stroke patients lack visual detectable signs of facial paralysis [11]. A study [4] reported that patients with stroke $(9.5 \mathrm{~N})$, patients with stroke and initial facial palsy $(8.3 \mathrm{~N})$, and patients with stroke without facial palsy $(11.0 \mathrm{~N})$ had weak lip strength, which was approximately $30-40 \%$ of that of healthy participants $(24.2 \mathrm{~N})$. These results suggest that a reason for the observed difference of lip strength and function between healthy individuals and stroke patients without facial palsy is because there is a subclinical facial paresis in stroke patients which results in weak lip function without ordinary signs of unilateral facial paresis [26]. 


\subsection{Lip Training Responses in Patients with Stroke}

Lip strength training for patients with stroke has been studied with interventions spanning from three [16] to five weeks $[4,11,13]$ (Table 2). Training with an acrylic Oral Screen placed directly behind closed lips that is horizontally pulled for sets of $5-10$ seconds have resulted in increased lip force [11]. Thus, lip muscle training supported earlier findings of its usefulness in treating dysphagia. Hägg and Anniko [4] followed up with a review article to understand the potential influence of lip function on swallowing capacity in patients with stroke, stroke with initial facial palsy, stroke without initial facial palsy, and healthy individuals and concluded that the changes in lip muscle function in patients with stroke were also able to improve the swallowing capacity in each population. Patients with stroke and dysphagia have demonstrated an increase in lip compression strength measured by the IOPI (10.5 to $12.8 \mathrm{kPa}$ ) following 3 weeks of orofacial myofunctional training [16]. After lip muscle training with the IOPI, the lip muscle strength showed a significant increase from 20.5 to $25.3 \mathrm{kPa}$ [13]. Similarly, when using electrical stimulation to the lip muscles (30 min/day, 5 days/week for 4 weeks), patients with dysphagia after stroke had an improvement in lip muscle strength measured by the IOPI (5.9 to $20.5 \mathrm{kPa}$ ) [27]. The change in lip muscle training in patients with stroke resulted in increased lip strength and function $[11,13,16,27]$.

\subsection{Lip Training Responses in Patients with Lip Incompetence}

Lip incompetence has been described as having a sealed lip ratio of less than $30.1 \%$ during relaxation and of less than $13.2 \%$ during concentration [28]. The sealed lip ratio is calculated as the total sealed-lip time divided by the total recorded time [28] or estimated using lip-contact sensor/electrical recording devices [29]. Lip strength training has been used for both men and women to improve lip incompetence [29-31]. Young men and women that partook in a 4 week intervention of lip endurance training with traction plates connected to a weight by strings displayed an increase in sealed lip ratio at 2 and 4 weeks after training but did not show differences after training ended (8 weeks) [29]. Along with the lip training protocol from Ohtusuka and colleagues [29], the results for strength and lip endurance did not differ pre- and post-training. Lip strength training using a traction plate inserted behind the lips connected to a weight by strings ( $80 \%$ of maximum tensile strength) for 4 weeks has been observed to increase strength [30]. Lip muscle strength was measured by traction plates pulled by a testing machine. The increase of lip strength was observed gradually during the training period from baseline (981.7 g) to 4 weeks (1372.7 g) of training [30]. This type of lip strength training was also evaluated in individuals with and without lip incompetence measured by electromyography activity, and it was suggested that individuals with lip incompetence need greater orbicularis oris muscle activity to keep their lips closed [31].

\section{Future Considerations}

In order to obtain a reliable measurement of lip force, it is important to ensure that the devices used for training utilize a method of squeezing the lips rather than sucking. For example, prefabricated oral screens or bottled water have a limitation, since participants can suck instead of actually squeezing their lips during training and/or measurement of their lip muscle strength. To obtain a reliable measurement of lip force, a method that induces squeezing of the lips without sucking should be adopted. In addition, there is a lack of studies on the impact of training variables (i.e., exercise intensity, volume, frequency, and training period) on lip strength training [32]. Future studies are needed to better determine if there are dose-response relationships in lip strength training in individuals with and without disease.

\section{Conclusion}

Lip strength appears to be higher in men than in women, regardless of age. Additionally, lip strength may be lower in much older populations ( $>80$ years) compared to young people. A variety of equipment is used for training interventions to improve lip strength and function. Furthermore, 
lip strength training has been shown to increase lip strength in both young and old healthy participants. However, since a variety of equipment is used for training interventions, standardized measuring tools and training equipment are necessary in the future. Although changes in strength have been observed in both men and women, we are unaware of any studies that have tested whether there are sex differences in this response. Similar benefits can be expected in patients with stroke and patients with lip incompetence, but the training effect could be higher in healthy people. Future research is necessary to discuss training methods and conditions that can be more effective. Until more work is completed investigating the impact of different training variables, specific recommendations related to lip strength training cannot be made.

Author Contributions: V.W., T.A., R.W.S., Z.W.B., Y.Y., R.N.C., and J.P.L. designed the study. V.W. and T.A. performed the review of the literature and wrote the manuscript. R.W.S., Z.W.B., Y.Y., R.N.C., and J.P.L. reviewed and critically revised the manuscript. All authors approved the final version of the manuscript.

Funding: This research received no external funding.

Conflicts of Interest: The authors declared no conflicts of interests with respect of the research, authorship, and publication of this articles.

\section{References}

1. Robbins, J.; Gangnon, R.E.; Theis, S.M.; Kays, S.A.; Hewitt, A.L.; Hind, J.A. The effects of lingual exercise on swallowing in older adults. J. Am. Geriatr. Soc. 2005, 53, 1483-1489. [CrossRef] [PubMed]

2. Takizawa, C.; Gemmell, E.; Kenworthy, J.; Speyer, R. A systematic review of the prevalence of oropharyngeal dysphagia in stroke, parkinson's disease, Alzheimer's disease, head injury, and pneumonia. Dysphagia 2016, 31, 434-441. [CrossRef] [PubMed]

3. Westergren, A.; Karlsson, S.; Andersson, P.; Ohlsson, O.; Hallberg, I.R. Eating difficulties, need for assisted eating, nutritional status and pressure ulcers in patients admitted for stroke rehabilitation. J. Clin. Nur. 2001, 10, 257-269. [CrossRef] [PubMed]

4. Hägg, M.; Anniko, M. Influence of lip force on swallowing capacity in stroke patients and in healthy subjects. Acta Otolaryngol. 2010, 130, 1204-1208. [CrossRef] [PubMed]

5. Nishiura, M.; Ono, T.; Yoshinaka, M.; Fujiwara, S.; Yoshinaka, M.; Maeda, Y. Pressure production in oral vestibule during gum chewing. J. Oral Rehab. 2015, 42, 900-905. [CrossRef] [PubMed]

6. Saladin, K. Anatomy \& Physiology: The Unity of Form and Function, 8th ed.; McGrawHill: New York, NY, USA, 2017; p. 319.

7. Kaede, K.; Kato, T.; Yamaguchi, M.; Nakamura, N.; Yamada, K.; Masuda, Y. Effects of lip-closing training on maximum voluntary lip-closing force during lip pursing in healthy young adults. J. Oral Rehab. 2016, 43, 169-175. [CrossRef]

8. Tamura, F.; Fukui, T.; Kikutani, T.; Machida, R.; Yoshida, M.; Yoneyama, T.; Hamura, A. Lip-closing function of elderly people during ingestion: Comparison with young adults. Int. J. Orofac. Myol. 2009, 35, $33-43$.

9. Takamoto, K.; Saitoh, T.; Taguchi, T.; Nishimaru, H.; Urakawa, S.; Sakai, S.; Ono, T.; Nishijo, H. Lip closure training improves eating behaviors and prefrontal cortical hemodynamic activity and decreases daytime sleep in elderly persons. J. Bodyw. Mov. Ther. 2018, 22, 810-816. [CrossRef]

10. Motta, L.J.; Bachiega, J.C.; Guedes, C.C.; Laranja, L.T.; Bussadori, S.K. Association between halitosis and mouth breathing in children. Clinics 2011, 66, 939-942. [CrossRef]

11. Hägg, M.; Anniko, M. Lip muscle training in stroke patients with dysphagia. Acta Otolaryngol. 2008, 128, 1027-1033. [CrossRef]

12. Ibrahim, F.; Arifin, N.; Rahim, Z.H.A. Effect of orofacial myofunctional exercise using an oral rehabilitation tool on labial closure strength, tongue elevation strength and skin elasticity. J. Phys. Ther. Sci. 2013, 25, 11-14. [CrossRef]

13. Park, H.S.; Park, J.Y.; Kwon, Y.H.; Choi, H.S.; Kim, H.J. Effect of orbicularis oris muscle training on muscle strength and lip closure function in patients with stroke and swallowing disorder. J. Phys. Ther. Sci. 2018, 30, 1355-1356.

14. Wertsén, M.; Stenberg, M. Measuring lip force by oral screens. Part 1: Importance of screen size and individual variability. Clin. Exp. Dent. Res. 2017, 3, 87-92. [CrossRef] 
15. IOPI Medical. Available online: https://iopimedical.com/about-us/ (accessed on 1 March 2020).

16. Byeon, H. Effect of orofacial myofunctional exercise on the improvement of dysphagia patients' orofacial muscle strength and diadochokinetic rate. J. Phys. Ther. Sci. 2016, 28, 2611-2614. [CrossRef] [PubMed]

17. Abe, T.; Bell, Z.W.; Wong, V.; Spitz, R.W.; Viana, R.B.; Yamada, Y.; Chatakondi, R.N.; Loenneke, J.P. A practical method for assessing lip compression strengthening in healthy adults. Cosmetics 2020, 7, 5. [CrossRef]

18. Clark, H.M.; Solomon, N.P. Age and sex differences in orofacial strength. Dysphagia 2012, 27, 2-9. [CrossRef] [PubMed]

19. Murakami, T.; Restle, J.; Ziemann, U. Effective connectivity hierarchically links temporoparietal and frontal areas of the auditory dorsal stream with the motor cortex lip area during speech perception. Brain Lang. 2012, 122, 135-141. [CrossRef]

20. Abe, T.; Wong, V.; Spitz, R.W.; Viana, R.B.; Bell, Z.W.; Yamada, Y.; Chatakondi, R.N.; Loenneke, J.P. Influence of sex and resistance training status on orofacial muscle strength and morphology in healthy adults between the ages of 18 and 40: A cross-sectional study. Am. J. Hum. Biol. 2020, 32, e23401. [CrossRef]

21. Jeong, D.M.; Shin, Y.J.; Lee, N.R.; Lim, H.K.; Choung, H.W.; Pang, K.M.; Kim, B.J.; Kim, S.M.; Lee, J.H. Maximal strength and endurance scores of the tongue, lip, and cheek in healthy, normal Koreans. J. Korean Assoc. Oral Maxillofac. Surg. 2017, 43, 221-228. [CrossRef]

22. Arakawa, I.; Koide, K.; Takahashi, M.; Mizuhashi, F. Effect of the tongue rotation exercise training on the oral functions in normal adults - Part 1 investigation of tongue pressure and labial closure strength. J. Oral Rehab. 2015, 42, 407-413. [CrossRef]

23. Fujiwara, A.; Tokura, K.; Tome, W.; Kitai, N. Multidirectional lip-closing force in adult females after short-term lip training. J. Oral Rehab. 2016, 43, 833-839. [CrossRef] [PubMed]

24. Szyszka-Sommerfeld, L.; Woźniak, K.; Matthews-Brzozowska, T.; Kawala, B.; Mikulewicz, M. Electromyographic analysis of superior orbicularis oris muscle function in children surgically treated for unilateral complete cleft lip and palate. J. Craniomaxillofac. Surg. 2017, 45, 1547-1551. [CrossRef] [PubMed]

25. Park, J.S.; You, S.J.; Kim, J.Y.; Yeo, S.G.; Lee, J.H. Differences in orofacial muscle strength according to age and sex in East Asian healthy adults. Am. J. Phys. Med. Rehab. 2015, 94, 677-686. [CrossRef] [PubMed]

26. Yildiz, N.; Ertekin, C.; Ozdemirkıran, T.; Yildiz, S.K.; Aydogdu, I.; Uludag, B.; Secil, Y. Corticonuclear innervation to facial muscles in normal controls and in patients with central facial paresis. J. Neurol. 2005, 252, 429-435. [CrossRef]

27. Oh, D.H.; Park, J.S.; Kim, W.J. Effect of neuromuscular electrical stimulation on lip strength and closure function in patients with dysphagia after stroke. J. Phys. Ther. Sci. 2017, 29, 1974-1975. [CrossRef]

28. Leonardo, S.E.; Sato, Y.; Kaneko, T.; Yamamoto, T.; Handa, K.; Iida, J. Differences in dento-facial morphology in lip competence and lip incompetence. Orthod. Waves 2009, 68, 12-19. [CrossRef]

29. Ohtsuka, M.; Kaneko, T.; Iida, J. Effectiveness of training methods to improve orbicularis oris muscle endurance in patients with incompetent lips. Orthod. Waves 2015, 74, 99-104. [CrossRef]

30. Yoshizawa, S.; Ohtsuka, M.; Kaneko, T.; Iida, J. Study of training for improving lip incompetence. Orthod. Waves 2016, 75, 47-53. [CrossRef]

31. Yoshizawa, S.; Ohtsuka, M.; Kaneko, T.; Iida, J. Assessment of hypoxic lip training for lip incompetence by electromyographic analysis of the orbicularis oris muscle. Am. J. Orthod Dentofac. Orthop. 2018, 154, 797-802. [CrossRef]

32. Saleem, M.; Yoshinari, N.; Nakamura, S.; Sumi, Y.; Iwai, Y.; Ozaki, Y.; Masuda, Y.; Uchida, K.; Taguchi, A. Improvement of salivary flow and oral wetness by a lip trainer device and sonic toothbrush in older Japanese men and women with dry mouth. J. Oral Sci. 2019, 61, 221-228. [CrossRef]

(C) 2020 by the authors. Licensee MDPI, Basel, Switzerland. This article is an open access article distributed under the terms and conditions of the Creative Commons Attribution (CC BY) license (http://creativecommons.org/licenses/by/4.0/). 